\section{Survival in memory clinic cohort is short, even in young- onset dementia}

\section{INTRODUCTION}

Patients with dementia have a shorter life expectancy compared with the general population. Survival time after diagnosis varies greatly however, with reported median survival times between 3 and 12 years. ${ }^{12}$ This variation could be due to many factors, such as type of dementia, patient characteristics and change in management over time. ${ }^{34}$

We aimed to study median survival times after a dementia diagnosis in a memory clinic-based cohort across different types of dementia, mild cognitive impairment (MCI) and subjective cognitive decline (SCD). Furthermore, we studied how age and sex influenced survival times. Finally, we studied whether median survival has changed over the past decades.

\section{METHODS}

From the Amsterdam Dementia Cohort, ${ }^{5}$ we included 4495 subjects with a baseline visit between 2000 and 2014 and a diagnosis of any type of dementia $(n=2625)$, MCI $(n=739)$ or SCD $(n=1131)$ who served as controls. The group of patients with dementia included 1690 dementia due to Alzheimer's disease (AD), 399 frontotemporal dementia (FTD), 165 vascular dementia (VaD) and 192 dementia with Lewy bodies (DLB). There were 179 with more rare causes of dementia, summarised as 'other dementias'. The study was approved by the local Medical Ethical Committee.

Information on mortality was obtained from the Dutch Municipal Register (accessed 14 September 2017). Survival duration was defined as years between date of baseline diagnosis and date of death or, when still alive, years between date of baseline diagnosis and 14 September 2017.

We determined median survival times using Kaplan-Meier analyses, per diagnosis and stratified for age and sex. Furthermore, we assessed whether median survival in our cohort had changed over the past decades. Finally, for illustrative purposes, we compared median survival per decade for dementia due to $\mathrm{AD}$ and non-AD (pooling FTD, VaD, DLB and other more rare causes of dementia), with median survival in the general Dutch population in 2000 and 2010. Detailed methods are provided in online supplementary file 1 .

\section{RESULTS}

Online supplementary table 1 presents the baseline characteristics of the patients according to diagnosis. Overall, mean age was age 66 610,2018 (45\%) were women and the mean Mini-Mental State Examination score was $24 \pm 5$. After a follow-up of $6.2 \pm 3.4$ years, $2072(46 \%)$ patients had died and 2423 (54\%) were still alive.

As for all types of dementia more than half of patients had died, we were able to determine a very precise estimate of median survival times. Median (95\% CI) survival time across the total group of dementia was short with 6.0 (5.8-6.2) years. Median survival time depended on the type of dementia, ranging from 6.4 (5.8-7.0) years in FTD, $6.2(6.0-6.5)$ years in dementia due to $\mathrm{AD}, 5.7(4.1-7.3)$ years in $\mathrm{VaD}, 5.1(4.5-5.7)$ years in DLB to 3.6 (3.2-4.0) for more rare causes of dementia (including Creutzfeldt-Jakob's disease) (figure 1A and online supplementary table $2)$. When comparing younger ( $\leq 65$ years) and older ( $>65$ years) patients, median survival time hardly differed. Survival was shorter in men for most types of dementia, except for FTD, where women had shorter survival.

Subsequently, we evaluated how median survival estimates changed over time (cohort effect). Online supplementary table 3 shows that median survival time increased from $5.3(4.8-5.7)$ in 2000 to 6.4 (5.6-7.3) years in 2010 (p.020). When we stratified for age, we observed that this effect seemed to be specific for late-onset patients, while in young-onset patients this trend over time was not observed.

Finally, we plotted median survival estimates in 2000 and 2010 by age bin in the general Dutch population next to patients with dementia due to $\mathrm{AD}$ and non-AD in 


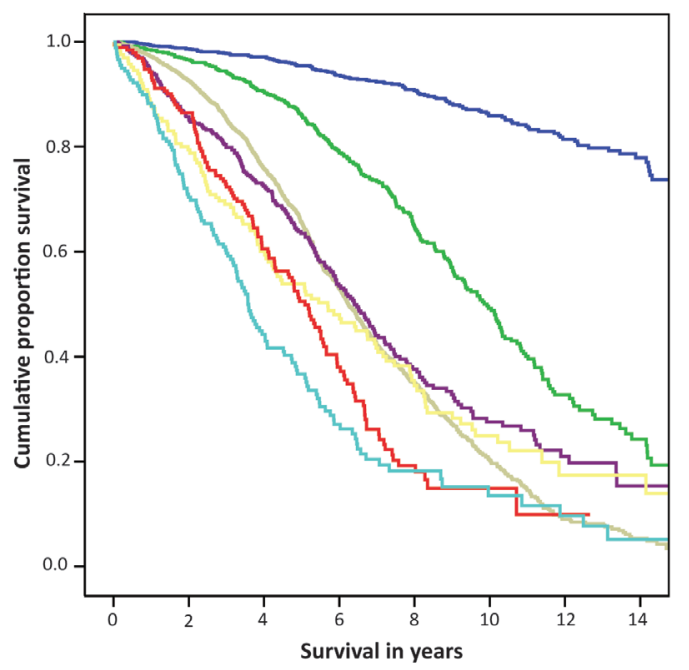

$\neg$ SCD
$\neg$ MCl
$\neg$ AD
$\neg$ FTD
$\neg$ VaD
$\neg$ DLB
$\neg$ 'Other' dementia

B

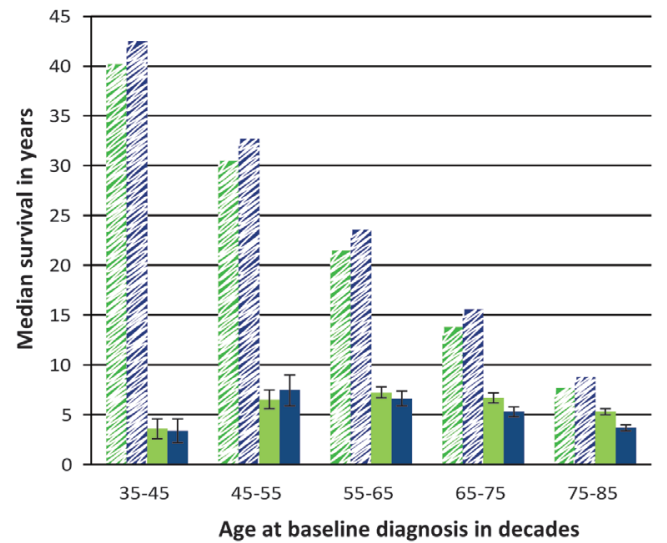

to the late-onset patients and comparable with the increase in life expectancy in the general Dutch population. By contrast, survival time in young-onset patients is similarly short.

A potential limitation of the current study is that our cohort is from a tertiary memory clinic, and so results may not accurately reflect survival time for dementia in general. However, our data provide an important extension of existing literature, which is mostly restricted to older patients with unspecified types of dementia. Among the strengths of our study is that we derived information on mortality from the Dutch Municipality registry, which is a reliable and up-to-date governmental owned registry, leading to complete and accurate data. All patients were selected from the same memory clinic where they underwent standardised diagnostic workup, and received comparable treatment and help with disease management.

In conclusion, median survival in patients with dementia is short, 6 years. Comparison with the general Dutch population shows that every type of dementia infers a strongly increased risk of mortality. This provides evidence for the notion that neurodegenerative diseases causing dementia are lethal, especially in youngonset patients. Despite increased awareness, median survival of these younger patients has not changed between 2000 and 2014. The fear that increased awareness would lead to (too) early diagnosis with ensuing too many years lived with a diagnosed disease that can as yet not be cured seems ungrounded.

Hanneke Frederica Maria Rhodius-Meester, ${ }^{1}$ Betty M Tijms, ${ }^{1}$ Afina W Lemstra, ${ }^{1}$ Niels D Prins, ${ }^{1}$ Yolande A L Pijnenburg, ${ }^{1}$ Femke Bouwman, ${ }^{1}$ Philip Scheltens, ${ }^{1}$ Wiesje M van der Flier ${ }^{1,2}$

${ }^{1}$ Alzheimer Center, Department of Neurology, VU University Medical Centre, Amsterdam Neuroscience, Amsterdam, The Netherlands

${ }^{2}$ Department of Epidemiology and Biostatistics, VU University Medical Center, Amsterdam Neuroscience, Amsterdam, The Netherlands

Correspondence to Hanneke Frederica Maria Rhodius-Meester, Alzheimer Center, VU University Medical Center, Amsterdam 1007 MB, The Netherlands; h.rhodius@vumc.nl

Acknowledgements Research of the VUmc Alzheimer Center is part of the neurodegeneration research programme of the Amsterdam Neuroscience. The VUmc Alzheimer Center is supported by Alzheimer Nederland and Stichting VUmc fonds. The clinical database structure was developed with funding from Stichting Dioraphte. WMvdF holds the Pasman chair. HFMR-M is appointed on a grant from the European Seventh Framework Program project PredictND under grant agreement 611005.

Contributors HFMR-M drafted the manuscript and analysed/interpreted data. BMT revised the manuscript and analysed/interpreted data. AWL, NDP, YALP, FB and
The main finding of this study is that after diagnosis in a memory clinic, median ee an increase in median survival time over time, but this observation is restricted 
PS revised the manuscript and interpreted data. WMvdF drafted the manuscript, analysed/interpreted data and supervised the project.

Funding The authors have not declared a specific grant for this research from any funding agency in the public, commercial or not-for-profit sectors.

Competing interests HFMR-M, BMT, AWL, YALP and FB report no disclosures. NDP serves on the advisory board of Boehringer Ingelheim and Probiodrug and on the DSMB of Abbvie's M15-566 trial. He has provided consultancy services for Sanofi, Takeda and Kyowa Kirin Pharmaceutical Development. He is CEO and co-owner of the Brain Research Center, Amsterdam, The Netherlands. PS has served as consultant for Wyeth-Elan, Genentech, Danone and Novartis and received funding for travel from Pfizer, Elan, Janssen and Danone Research. WMvdF performs contract research for Biogen. Research programmes of WMvdF have been funded by ZonMW, NWO, EU-FP7, Alzheimer Nederland, CardioVascular Onderzoek Nederland, stichting Dioraphte, Gieskes-Strijbis fonds, Boehringer Ingelheim, Piramal Neuroimaging, Roche BV and Janssen Stellar. All funding is paid to her institution.

Patient consent Obtained.

Ethics approval Medische Ethische Toetsingscommisie VUmc Amsterdam.

Provenance and peer review Not commissioned; internally peer reviewed.

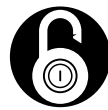

\section{OPEN ACCESS}

Open access This is an open access article distributed in accordance with the Creative Commons Attribution Non Commercial (CC BY-NC 4.0) license, which permits others to distribute, remix, adapt, build upon this work non-commercially, and license their derivative works on different terms, provided the original work is properly cited, appropriate credit is given, any changes made indicated, and the use is non-commercial. See: http:// creativecommons.org/licenses/by-nc/4.0/

(c) Author(s) (or their employer(s)) 2019. No commercial re-use. See rights and permissions. Published by BMJ.

- Additional material is published online only. To view please visit the journal online (http://dx.doi.org/ 10.1136/jnnp-2018-318820).

\section{A) Check for updates}

To cite Rhodius-Meester HFM, Tijms BM, Lemstra AW, et al. J Neurol Neurosurg Psychiatry 2019;90:726-728.

Received 14 May 2018

Revised 12 June 2018

Accepted 10 July 2018

Published Online First 25 July 2018

J Neurol Neurosurg Psychiatry 2019;90:726-728.

doi:10.1136/jnnp-2018-318820

\section{REFERENCES}

1 Todd S, Barr S, Roberts M, et al. Survival in dementia and predictors of mortality: a review. Int I Geriatr Psychiatry 2013;28:24

2 Brodaty H, Seeher K, Gibson L. Dementia time to death: a systematic literature review on survival time and years of life lost in people with dementia. Int Psychogeriatr 2012;24:1034-45.

3 Garcia-Ptacek S, Farahmand B, Kåreholt I, et al. Mortality risk after dementia diagnosis by dementia type and underlying factors: a cohort of 15,209 patients based on the Swedish Dementia Registry. J Alzheimers Dis 2014;41:467-77

4 Kansal K, Mareddy M, Sloane KL, et al. Survival in frontotemporal dementia phenotypes: a meta-analysis. Dement Geriatr Cogn Disord 2016;41:109-22.

5 van der Flier WM, Pijnenburg YA, Prins N, et al. Optimizing patient care and research: the Amsterdam Dementia Cohort. J Alzheimers Dis 2014;41:313-27. 